\title{
INTELLIGENCE MOBILE AND DIGITAL BROADCASTING TECHNOLOGY TO SUPPORT LEARNING FOR DISABILITIES STUDENTS
}

\author{
${ }^{1}$ Settachai Chaisanit, ${ }^{1}$ Chiraphorn Chomyim and ${ }^{2}$ Samphan Chandee \\ ${ }^{1}$ School of Information Technology, \\ Sripatum University Chonburi Campus, Chonburi, Thailand \\ ${ }^{2}$ Departments of Business Information Technology, Faculty of Business Administration, \\ Rajamangala University of Technology, Rattanakosin, Thailand
}

Received 2013-04-26, Revised 2013-05-28; Accepted 2013-09-18

\begin{abstract}
Usage of mobile digital broadcasting technologies in education is the most important of required technologies to provide main goals in distance education. It offers learning and data accession opportunities to learners notwithstanding time and place. In academic education, it was found that one of the critical problem is the appreciate education tool for disabilities students. Students with special education have difficulties to develop cognitive abilities and acquire new knowledge. They could also need to improve their behavior, communication and relationships with their environment. The development of customizable and adaptable applications tailored to them provides many benefits as it helps mold the learning process to different cognitive, sensorial or mobility impairments. This reviewed paper defines mobile technologies universally designed devices and technology for learning, presents examples of how designed technology hardware and software applications promote increased learning to school and university settings to enhance learning outcomes of all students, including those with disabilities. The reviewed results found that application of the instrumental enrichment of mobile technologies universally designed devices and technology can have an effect in terms of anticipated effects and thus have a positive influence on both learning skills and results in school and university students with a learning disability. The students mainly appreciated the mobile devices and technology and optimistic approach to the learner and to possibilities of modification of their own learning style. The mobile device and technology provide students with options to access the content multiple times in different settings while using a variety of technology applications. The concluded results also challenged educators to rethink the nature of the disability students' curriculum and empower them with the flexibility to serve a diverse population of learners.
\end{abstract}

Keywords: Mobile Digital Broadcasting Technologies, Disability Student, Mobile Devices and Technology, Intelligence Mobile

\section{INTRODUCTION}

To serve disabled students an appropriate system in physical access to building and the curriculum of teaching, learning and assessment is a pose challenges to academy. The ability of individual with disability in education should be concern included a diverse range of learners, especially relevant in terms of highlighting the initiative of expanding access to higher education by focusing on the participation of individuals who promote the underrepresented groups (Roeden et al., 2012). According to their special needed, most of the disabled students experienced barriers to accessing their education relating to the basic circumstance such as physical parameter and education process and methodology. In addition, the disabled student tended to choose a course Corresponding Author: Settachai Chaisanit, School of Information Technology, Sripatum University Chonburi Campus, Chonburi, Thailand 
and institution that they have no affected with accessibility. Some students found that adjustments to teaching practices were difficult to obtain. Even where students had received the reasonable adjustments such as handouts in advance of lectures, but they often found themselves a trouble in teaching and learning process. Some lecturers, particularly in old school universities, felt that the adjustments of teaching practices would affect the learning standards and give insufficient advantage to disabled students. Moreover, academic staffs that have responsibility in those courses usually were under pressure and were unable to connect with individual students (King et al., 2013).

There is numerous researchers report to the gap in education accessibility between students with and without disabilities, resulting in limited opportunities to gain high skill employment (Roeden et al., 2012). Statistics on the science and engineering workforce show that only about $7 \%$ of graduate students in science and engineering were persons with disabilities (King et al., 2013).

There are observations that school and university are willing to make physical accommodations for students with disabilities, but creating a welcoming climate has yet to follow suit. Universal design for learning strategies addresses these inequities by enhancing the quality of higher education through the creation of more flexible and student-centered learning environments (Kochhar-Bryant et al., 2008). The Mobile learning, or M-learning, has become a new educational paradigm, gaining popularity especially at institutions of higher learning education. This strategy enhance learning for all students, including students with disabilities who are majoring in Science, Technology, Engineering and Math (STEM), one of the most rigorous academic disciplines, but also one of the most financially rewarding careers (Rose and Meyers, 2010).

This paper defines the Mobile learning device, presents examples of how universally designed technology hardware, software and tech applications promote increased learning and finally, discusses how professors integrate M-learning strategies into university settings to enhance learning outcomes for all disability students. Students entering school or university are more diverse, including international students with varied ethnic and cultural backgrounds; and students with an array of learning, attention, psychological and physical disabilities (Sevo, 2011). This increase in the number of diverse students challenges professors to embrace a wide range of students and address needs of students with disabilities to make higher education more accessible (Abas et al., 2009). To help address these challenges, legislation, educational research and teaching practice promote M-learning as a strategy for raising academic standards for all students. This paper discusses how Mlearning teaching practices enhance the engagement and achievement of students with disabilities, an underrepresented population within the STEM disciplines (Newman et al., 2010).

\section{MOBILE DIGITAL BROADCASTING FOR LEARNING}

Ongoing development of information technology in the modern era has increased the limits of the technology available to meet the needs of the people. While technological devices and usage of these were subject to a specific environment or location in the past, environment and location now have their independent specialties for the past recent times. Mobile learning or M-learning is a type of learning that gains the benefits and opportunities by mobile technologies which availability, adapt learning content to the context the learner finds in and taking place both inside and outside the classroom across formal and informal settings (ZadahmadJafarlou et al., 2011). M-learning shows the combination of mobile informatics and e-learning fields. The content of e-learning is available from any location, utilization of services system created forcible in communication with others. Learning adjusted according to location and circumstances (Newman et al., 2010).

In an M-learning environment, knowledge can be transmitted via the mobile phones, laptops, tablet PCs and PDAs. M-learning places emphasis on the fact that the teaching and learning process can take place without being constrained by time and location. In other words, teaching and learning can be carried out at anytime and anywhere. There is greater learner mobility. Using their mobile phones, students can receive and share notes and materials. They do not need a computer to download notes because the mobile phone with internet access can carry out this function anywhere and anytime.

With advances in information technologies, mobile communication devices have become important tools to interconnect people quickly. For people with disabilities, however, these services are often unavailable, since they require proper adaptive tools and special interfaces in order to use conventional mobile devices. Consequently, development and production of high-tech adaptive tools is needed for physically and psychological impaired users in order to assist them with self-learning and personal development, so that they can become more independent in their daily lives. Among the numerous technological adaptive devices and tools available, many are based on the adaptation of hardware and software. 
These devices can be applied in training, teaching, learning, rehabilitation, communication and adaptive design (Roeden et al., 2012; Newman et al., 2010).

\section{M-LEARNING UNIVERSALLY DESIGNED DEVICES AND TECHNOLOGY}

\begin{abstract}
Designing inclusive learning environments using technology creates optimal conditions for accommodating the changing needs of multiple constituents (Rose and Meyers, 2010). Courses designed using principles of M-learning and supported by universally designed technology provide students with options to access the content multiple times in different settings while using a variety of technology applications. With the growth of the Internet and technological innovations, many learning environments include computers and other devices that help students learn more efficiently. According to many recently researches (Simpson et al., 2010; Graves et al., 2011), computer software provides assistance to students with disabilities and other learning challenges gain access to course content that prior to the digital age were unavailable to learners with special needs. These M-learning universally designed devices and technology can reduce the need for formal accommodations for school and university students with disabilities. Examples of several different types of technology are provided in the discussion which mentioned as followed.
\end{abstract}

\subsection{Digital Pen with Audio Recording}

The digital pen converts handwritten notes into digital records so students can transfer their notes to a personal computer. Once digitized, students can edit, highlight and review their notes as they study for tests or prepare projects. Students can transfer key concepts to Microsoft PowerPoint ${ }^{\circledR}$ or Excel ${ }^{\circledR}$ documents or insert examples from other sources such as class texts or related websites. Digital pens provide opportunities to engage students in the content using both audio and visual supports, therefore maximizing two learning modalities and ultimately increasing engagement with the content, often resulting in increased achievement. Digital pens provide a critical support for students, both with and without disabilities (Graves et al., 2011).

\subsection{Tablet PC}

Tablet PC is rapidly becoming essential for participation in social, personal and occupational activities. Due to the convenience and flexibility in design, including easy manipulation of the touch interface, this technology, with the internet supported, is frequently found in public settings and service for people with disabilities.

The ubiquitous nature of the tablet PC and internet may provide continuous access to lecture content developed and digitally archived through another computers applications. Nowadays, the Tablet PC using innovative such as digital pen technology provides a tool that educators can use in designing learning environments that may engage most learners.

Moreover, in several studies, researchers reported that using Tablet PCs to record lectures with audio and visual displays enhanced the achievement of students with disabilities (Graves et al., 2011). This example and others are discussed to demonstrate how technological supports increase success of all students, including students with disabilities, regardless of educational level or setting.

\subsection{The RFID Supported Mobile-learning for Persons with Physical Disabilities}

Augmented Reality (AR) has been acclaimed as one of the promising technologies for advancing future of universally designed devices and technology. AR has been increasingly noted as a mediator between the physical space and computing space by associating virtual information processed by a computer with the current physical environments of the end-user. Despite a myriad of AR applications and its influence on the human-computer interaction field, end products that integrate AR are less commonplace than expected. This is due to a lack of being able to forecast in which direction mainstream standardization of AR-oriented platform components will be framed. Then, the researchers were looking for the instead or supplementary technology that can fulfilled the gap and those new technology came out to be the RadioFrequency Identification or RFID (Domingo, 2012).

Radio-frequency identification (RFID) is a wireless sensor technology which is based on the detection of electromagnetic signals. A typical RFID system includes three components: an antenna or coil, a transceiver (with decoder) and a transponder ( $\mathrm{RF}$ tag) electronically programmed with unique information. Currently, the RFID systems are applied in different areas (Zhu et al., 2012). There are many report proposes on an intelligent deployment system for RFID readers and system feasibility studies of RFID applications. In recent years, with the upsurge of the second generation of the Internet of Things, integrating the RFID technology and the Internet of Things and using them to support the education process of people with disabilities (Fig. 1). 


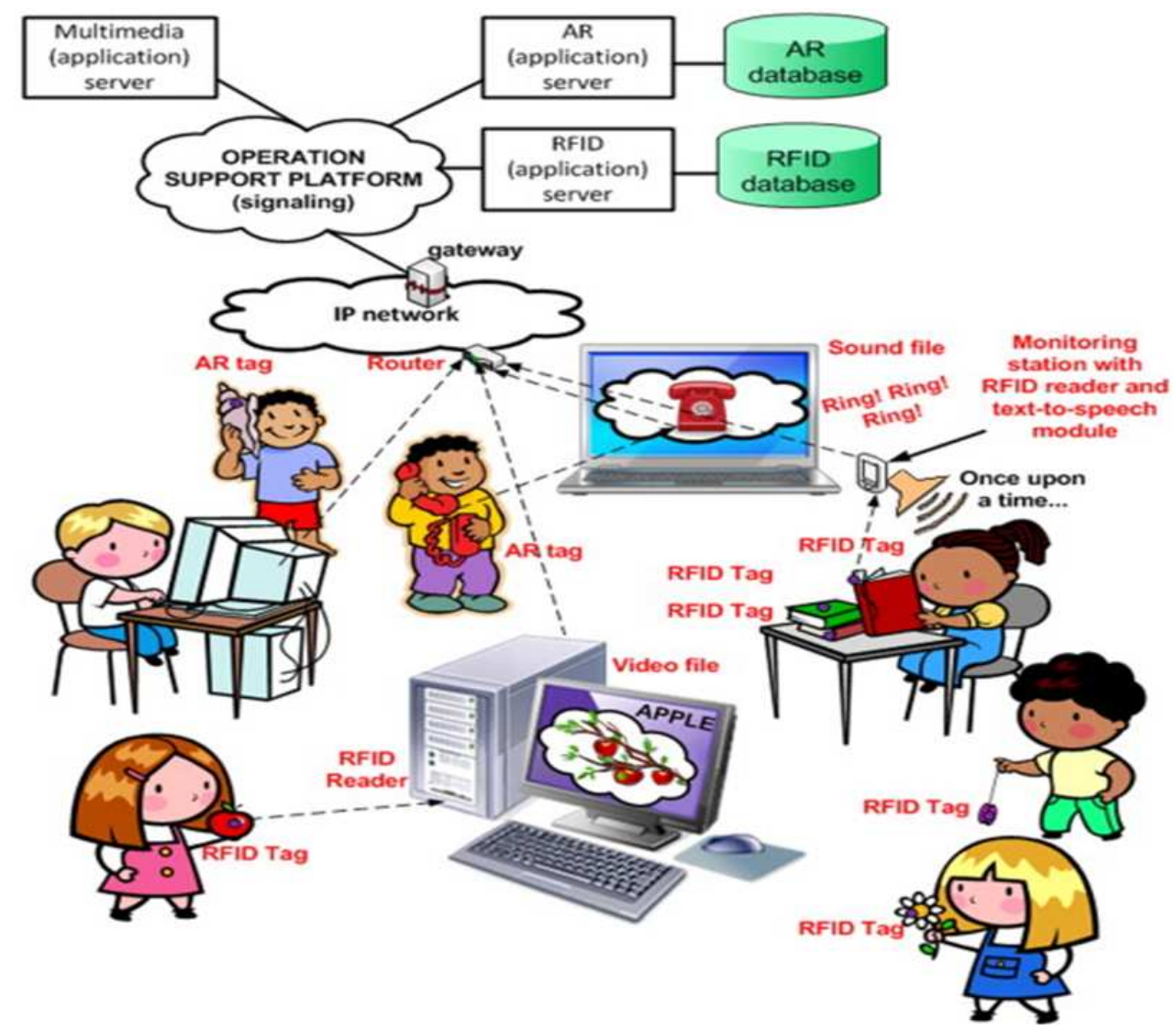

Fig. 1. The use of RFID supported mobile digital broadcasting for learning in school scenario (Domingo, 2012)

The use of this technology can offer people with disabilities the assistance and support they need to achieve a good quality of life and allows them to participate in the social and fulfill their education life.

\subsection{The AAC Device for Students with Developmental Disabilities}

Person with developmental disorder usually face problem on impairments in social skills, communication skills and imagination (Toran et al., 2010). The students with developmental disorder really need an individual plan and technology to support their education. The Augmentative and Alternative Communication (AAC) system is one of the M-learning technologies that often applied in education system of developmental disorder student. There are recently researches that report with the utilization of AAC. For example, Meer et al. (2011) report the results relative to $\mathrm{AAC}$ in their research "Assessing preferences for AAC options in communication interventions for individuals with developmental disabilities: A review of the literature". They synthesized studies that assessed preference for using different AAC options such as Speech-Generating Devices (SGD), Picture Exchange (PE) systems and manual signs. Their results showed that AAC system appeared to be the useful support device for students with developmental disabilities and indicate that individuals often show a preference for different AAC options which enable individuals to exert some degree of independent judgment with respect to AAC intervention. Ganz et al. (2011) report the useful benefit of AAC aids that can support the participant characteristics of individuals with Autism Spectrum Disorders (ASD). Their result also indicated that participants with ASD and no additional diagnoses had better outcomes than others and that participants with ASD and developmental disabilities outperformed participants with ASD and multiple disabilities. 


\section{5. iPad/iPodTouch ${ }^{\circledR}$}

The $\mathrm{iPad}^{\circledR}$ is a tablet computer, built-in keyboard, digital video camera and Internet connectivity and the iPodtouch $^{\circledR}$ is a smaller handheld device with similar capabilities as the iPad. Over 200,000 apps are available for download to the iPad or iPodTouch. Apple ${ }^{\circledR}$ designed accessibility features into both of these devices. For consumers with vision loss, the $\mathrm{iPad}^{\circledR}$ and iPodTouch ${ }^{\circledR}$ has VoiceOver technology which will audibly speak what is on the screen and what the user is interacting with. For those with limited vision, the iPodTouch ${ }^{\circledR}$ touch has a color inverting features to enable white text on a dark background. The contents of the screen can be enlarged or zoomed. Numerous researchers are incorporating these devices and various apps to provide instruction or supports for persons with disabilities (Buckley, 2009). Examples of several studies were showed as follow.

Communication App: The Speakall! App is a useful customizable program that helps students with autism improve their basic and academic accessibility especially communication and classroom behavior skills. The Speakall! App was developed by the Engineering Project In Community Service (EPIC), a team of engineers and undergraduate students at Purdue University in Indiana. The app uses traditional communication aides such as low-tech picture exchange communication system in which children trade pictures for items desired and a mid-tech electronic device that speaks out constructed sentences. Student need to drop and drag or touch images to construct sentences that the $\mathrm{iPad}^{\circledR}$ then speaks for them. This app has been used by both elementary and high school students with severe disabilities, including autism (PU, 2012a).

Daily Living Skills: The used of iPod ${ }^{\circledR}$ touch to teach cooking skills to high school students with severe disabilities using video prompting and activity schedules. Students learned to follow an activity schedule that was programmed to an $\mathrm{iPod}^{\circledR}$ touch and then followed video prompts to complete the tasks within the schedule. Students generalized the skills learned to other settings and activity schedules (PU, 2012b).

\section{CONCLUSION}

Mobile Digital Broadcasting for learning has a huge potential to transform and revolutionize the learning process. Mobile gadgets such as the hand phone, Personal Digital Assistant, internet technology, Smart phone and $\operatorname{iPod}^{\circledR}$ not only allow the user to communicate or be entertained, but they also support M-learning. This review study showed that school and university students, both with and without disabilities, have personal innovativeness and are ready embrace Mobile Digital Broadcasting for learning as an integral part of their learning process. The review literatures also found that the instructors are attuned to the need for greater flexibility in instructional design while maintaining high standards to teach students with and without disabilities. M-learning universally designed devices and technology offers a promising approach to meeting the learning needs of all students. The M-learning framework challenges educators to rethink the nature of their curriculum and empowers them with the flexibility to serve a diverse population of learners. Researchers must further develop and validate universal design principles and strategies across contexts and constituencies, so that more students with diverse backgrounds continue to access and succeed in education and gain the skills needed to join the workforce and make significant contributions to our global community.

\section{ACKNOWLEDGMENT}

This study has been done exceptional thanks to committee of Sripatum University Chonburi Campus. Without their guidance and support, this study would not have taken its current form, nor would it have come to completion. Foremost, I would also like to thank the people in the school of Information Technology for their support and thanks also to the Dr. Tau-Tong Pungsuwan and Asst. Prof. Dr. Ratchadawan Nimnual for making some useful comments on both the concept of the evolutionary approach and a draft of the study.

\section{REFERENCES}

Abas, Z.W., C.L. Peng and N. Mansor, 2009. A study on learner readiness for mobile learning at open university Malaysia. Proceedings of the IADIS International Conference on Mobile Learning, (CML' 09), pp: 151-157.

Buckley, K., 2009. Accessibility for iPhone, iPad and iPod touch: A blind user's review. Nillabyte LLC.

Domingo, M.C., 2012. An overview of the internet of things for people with disabilities. J. Netw. Comput. Applic., 35: 584-596. 
Ganz, J.B., T.L. Earles-Vollrath, R.A. Mason, M.J. Rispoli and A.K. Heath et al., 2011. An aggregate study of single-case research involving aided AAC: Participant characteristics of individuals with autism spectrum disorders. Res. Autism Spectrum Disorders, 5: 1500-1509. DOI: 10.1016/j.rasd.2011.02.011

Graves, L., P.A. Asunda, A. Paul, S.J. Plant and C. Goad, 2011. Asynchronous online access as an accommodation on students with learning disabilities and/or attention-deficit hyperactivity disorders in postsecondary STEM courses. J. Postsecond. Educ. Disabil., 24: 317-330.

King, M., N. Shields, C. Imms, M. Black and C. Ardern, 2013. Participation of children with intellectual disability compared with typically developing children. Res. Dev. Disabilities, 34: 1854-1862. DOI: $10.1016 /$ j.ridd.2013.02.029

Kochhar-Bryant, C., D.S. Bassett and K.W. Webb, 2008. Transition to Postsecondary Education for Students with Disabilities. 1st Edn., Corwin Press, Thousand Oaks, ISBN-10: 1412952794, pp: 237.

Meer, L.V.D., J. Sigafoos, M.F. O'Reilly and G.E. Lancioni, 2011. Assessing preferences for AAC options in communication interventions for individuals with developmental disabilities: A review of the literature. Res. Dev. Disabil., 32: 1422-1431. DOI: 10.1016/j.ridd.2011.02.003

Newman, L., M. Wagner, R. Cameto, A.M. Knokey and D. Shaver, 2010. Comparisons Across Time of the Outcomes of Youth with Disabilities Up to 4 Years After High School: A Report of Findings from the National Longitudinal Transition Study-2 (NLTS2). Institute of Education Sciences.

PU, 2012a. Develope 'SpeakAll' App to Help Children with Severe Autism. Purdue University. Global Accessibility Retrieved.
PU, 2012b. Purdue students develop app to help children with severe autism. Purdue University.

Roeden, J.M., M.A. Maaskant, H.M. Koomen, M.J. Candel and L.M. Curfs, 2012. Assessing clientcaregiver relationships and the applicability of the 'student-teacher relationship scale' for people with intellectual disabilities. Res. Dev. Disabil., 33: 104110. DOI: 10.1016/j.ridd.2011.08.027, PMID: 22093654

Rose, D.H. and A. Meyers, 2010. Universal Design for Learning. International Encyclopedia of Education. 3rd Edn., Imprint Elsevier Publishing, pp: 124.

Sevo, R., 2011. Basics about Disabilities and Science and Engineering Education. Lulu Press, Inc.

Simpson, R., H.H. Koester and E. LoPresti, 2010. Research in computer access assessment and intervention. Phys. Med. Rehabil. Clin. N. Am., 21: 15-32. DOI: 10.1016/j.pmr.2009.07.006

Toran, H., M.H.M. Yasin, F. Chiri and M.M. Tahar, 2010. Monitoring Progress using the individual education plan for students with autism. Proc. Soc. Behav. Sci., 7: 701-706. DOI: 10.1016/j.sbspro.2010.10.095

ZadahmadJafarlou, M., B. Arasteh and P. YousefzadehFard, 2011. A pattern-oriented and web-based architecture to support mobile learning software development. Proc. Soc. Behav. Sci., 28: 194-199. DOI: 10.1016/j.sbspro.2011.11.037

Zhu, X., S.K. Mukhopadhyay and H. Kurata, 2012. A review of RFID technology and its managerial applications in different industries. J. Eng. Technol. Manage., 29: 152-167. DOI: 10.1016/j.jengtecman.2011.09.011 